\title{
Economia Política e as raízes da posição original em Rawls
}

\author{
Fabrício Pontin \\ fpontin@gmail.com \\ Southern Illinois University, Illinois, USA
}

resumo 0 impacto e a relevância da teoria econômica para o desenvolvimento de $A$ Theory of Justice são, frequentemente, deixados de lado na imensa literatura a respeito das obras de John Rawls. Ainda assim, entender os elementos de economia política na obra de Rawls é fundamental para a compreensão dos motivos pelos quais ele abandonará uma abordagem utilitarista para a filosofia política e, consequentemente, para nosso entendimento das principais questões que dão origem à noção de justiça como equidade. Este artigo tem dois objetivos principais: primeiramente, descrever a influência de John Stuart Mill, Kenneth Arrow e Vilfredo Pareto na virada metodológica encontrada na ideia de posição original; segundo, descrever os elementos históricos pressupostos para a compreensibilidade dos ideais rawlsianos. Concluirei com algumas observações que sugerem um complemento historicista e fenomenológico para as descrições ideais encontradas no liberalismo político tal como é entendido por Rawls.

palavras chave Economia Política; Liberalismo Político; Posição Original; Escolha Racional.

Em 1929, Wittgenstein apresentou, em Cambridge, uma conferência sobre ética. Essa seria a única vez que o autor dedicou-se a esse tópico. $\mathrm{O}$ artigo mostra a imensa dificuldade em estabelecer uma linguagem na qual poder-se-ia lidar com questões éticas e de constituição de valor. A "corrida contra os limites dentro dos quais nos encontramos" " descrito por Wittgenstein oculta um preocupação peculiar: afirmações sobre questões éticas são possíveis? Ou seja, essas afirmações podem ser consideradas verdadeiras ou falsas? Isso nos leva de volta à questão sobre o que nos permite

Recebido em 30 de janeiro de 2013. Aceito em 01 de março de 2013.

Texto traduzido para o português por Dr. WalterValdevino (Filosofia, UFRRJ).

doispontos, Curitiba, São Carlos, vol. 10, n. 1, p.83-101, abril, 2013 
dizer que um objeto "q" tem propriedades "z", "y" ou "a" que nos permitem falar daquele objeto como sendo "q", e, caso essas propriedades deixem de se aplicar a "q", se "q" deixaria de ser o caso. Isso é facilmente verificável quando lidamos com objetos físicos ou com fatos da natureza, em relação aos quais afirmações de "caso" podem ser, ao menos prima facie, fáceis de indicar. É verdadeiro que força é igual a massa vezes aceleração, é verdadeiro que um corpo permanece em repouso até que algo perturbe essa condição e é verdadeiro que a cor preta do teclado em que digito este texto é o resultado da interação de ondas de luz que possuem velocidade aproximada de $3.0 \times 10^{8} \mathrm{~m} / \mathrm{s}$. Mas essas afirmações estão reproduzindo leis da fisica, e temos uma linguagem particular para lidar com essas leis - claro que essa é uma linguagem imperfeita, mas mesmo com esse proviso em mente, dificilmente alguém encontraria uma hipótese que indicasse que a inércia não existisse. Mas o que podemos dizer em relação a julgamentos de valor?

Se as tradições alemã e francesa concentraram-se nas condições especulativas para a teoria moral e na conexão entre o moral e o legal, a modernidade inglesa e a americana são marcadas por um acentuado foco na economia. Talvez isso seja o reconhecimento dos limites da teoria moral: já que não podemos apreender completamente os processos de constituição de valor e identidade, poderíamos nos concentrar em como estabelecer preferências e em como essas preferências resultam em dinâmicas de troca de valor. Isso também leva ao reconhecimento de que a organização constitucional do dissenso social torna-se uma tendência irresistível na política europeia depois da Paz de Westphalia - e tal organização constitucional traz consigo a organização burocrática do capitalismo.

Nesse sentido, Rawls está certo, em 1974², quando decide concentrar-se nos elementos da política econômica no utilitarismo de modo a construir sua crítica aos modelos de vantagem comparativa da filosofia política. Isso tem dois motivos: primeiro, a confirmação de que, depois do reconhecimento da prevalência dos direitos, não há mais controvérsia no debate em relação a que valores devem ser considerados universais ${ }^{3}$; em segundo lugar, depois do surgimento da teoria liberal dos direitos, a teoria econômica é o único tipo de doutrina abrangente que precisa ser questionada em termos políticos: novamente, o foco é em como direitos devem ser implementados e não em por que devem ser implementados ${ }^{4}$. 
Não é coincidência que Rawls faça muitas de suas reflexões partindo das pressuposições construídas por Pareto e, depois, por Arrow ${ }^{5}$. E foi justamente Arrow que foi capaz de provar que o complexo sistema de Pareto para o equilíbrio social era possível, pelo menos matematicamente, em uma situação ideal. Mas ele também indicou discrepâncias matemáticas no desenvolvimento geral de um sistema democrático. Ou seja, mesmo em condições bastante mínimas, seria praticamente impossível, do ponto de vista da economia política, estabelecer uma fórmula matemática sólida para um sistema democrático.

Gostaria, agora, de desenvolver as condições, do ponto de vista da economia política, que permitirão a Rawls construir um núcleo metodológico para sua defesa das políticas liberais. Rawls descreve o processo de escolha social e preferências que leva ao desenvolvimento de sociedades liberais. Tal descrição ocorre de acordo com a teoria da escolha racional e a teoria utilitarista, que Rawls tenta superar com sua própria versão de uma descrição universalista e baseada em princípios a respeito da supremacia de direitos.

Nesse sentido, devemos entender quais elementos da teoria econômica são fundamentais para o desenvolvimento da magnus opus de Rawls. Enfrentar tais elementos permitir-nos-á identificar as principais questões encontradas por Rawls na teoria utilitarista. Tais questões, parece-me, não são de origem filosófica, mas econômica.

Tanto quanto diz respeito à economia política, todo o debate sobre preferências gira ao redor de uma única ideia desenvolvida por Stuart Mill: a noção de "critério de preferência para a decisão". No quarto capítulo de sua obra-prima Utilitarismo, Mill antecipa os duzentos anos seguintes de debate sobre escolha racional com uma simples sucessão de afirmações sobre preferências. Primeiro, Mill sugere que é possível preferir um prazer em relação a outro. Assim, se um prazer é visto como tendo uma ordem superior ao de outro, é razoável assumir que indivíduos que experimentam esses prazeres de ordem superior buscarão atividades e experiências que levem a esses prazeres. E eles irão, certamente, evitar atividades e experiências que farão com que esse prazer desejado cesse ou desapareça. Também é possível preferir evitar meios para alcançar um certo prazer (mesmo de ordem superior) se as circunstâncias levarem a tal desconforto que o prazer obtido se torne, nesse contexto, insignificante. 
Nesse sentido, se eu realmente gosto de sorvete de limão, buscarei experiências que me levem a obter sorvete de limão - ao invés de sorvete de chocolate, que eu não gosto. Entretanto, se as circunstâncias fizessem com que eu fosse torturado, ou me fizessem matar bebês jogando-os contra uma parede, ou me fizessem comer sorvete de chocolate para que eu pudesse comer sorvete de limão, então seria perfeitamente razoável preferir não obter sorvete de limão.

Assim, o que é fundamental para a própria possibilidade de conceber tais prazeres é que os indivíduos sejam capazes de desenvolver "hábitos de autoconsciência e auto-observação" ". Isso significa que uma decisão a respeito de preferências, particularmente as de alta ordem, têm de ser, de algum modo, uma decisão informada, ou seja, indivíduos que decidem com base em preferências estão tomando decisões com algum grau de consciência a respeito da cadeia causal que leva da experiência ao prazer, e são capazes de entender, pelo menos, algumas das intricadas sutilezas de tal cadeia causal. Além disso, Mill acredita que as pessoas têm preferências porque elas têm preferências. Ou seja, elas são afetadas apenas de modo marginal por fatores externos e vantagens circunstanciais (embora, como eu tenha mencionado, haja um proviso para certos meios para se alcançar um fim que poderia implicar em sofrimento ou desconforto de uma ordem superior àquela da preferência em vista).

\section{a) Alguns exemplos da Eficiência de Pareto nos processos de escolha}

Primeiramente, precisamos entender que a Eficiência de Pareto lida com dois cenários possíveis. Por um lado, temos um cenário no qual a estratégia dominante é dada de modo que cada agente que escolha possa ter as melhores opções possíveis à disposição (ou, pelo menos, que possa conceber essa possibilidade em uma situação ideal). Por outro lado, temos cenários nos quais a estratégia dominante não é dada dessa forma e as melhores escolhas desejáveis não estão à disposição dos agentes.

Assim, suponhamos que haja dois agentes escolhendo frutas em uma situação na qual 100 indica a escolha favorita, 50 é aceitável e 0 é inaceitável. 
Escolhas para o agente1
a) Uvas - 100
b) Pomelo - 51
c) Limão - 1

Escolhas para o agente2
a) Limão - 100
b) Pomelo - 51
c) Uvas - 1

Assim, evidentemente, em todos os casos nos quais 1 ou 2 estão escolhendo de modo independente um do outro e têm todas as três possibilidades sem qualquer espécie de interferência, eles escolherão independentemente (a), de modo a garantir a máxima satisfação. Esse é um cenário max-max.

Entretanto, em uma situação ideal na qual indivíduos estão escolhendo bens escassos, tais cenários são um pouco diferentes.

Suponhamos um cenário no qual diferentes escolha possíveis são dadas aos atores $\mathrm{A}(\mathrm{x})$ e $\mathrm{B}(\mathrm{y})$ :

\begin{tabular}{|l|l|l|l|}
\hline & & \multicolumn{2}{|c|}{$\mathrm{B}$} \\
\hline & & 1 & 2 \\
\hline \multirow{2}{*}{$\mathrm{A}$} & 1 & 100,1 & 50,50 \\
\cline { 2 - 4 } & 2 & 50,1 & 1,100 \\
\hline
\end{tabular}

Nesse caso, é factível que indivíduos optarão por sua escolha preferida (100), de modo a não prejudicar a escolhas possíveis para (B). Esse é uma Eficiência de Pareto fraca, ou seja, indivíduos, em uma situação ideal, podem escolher estados factíveis.

Ademais, isso pressupõe que os indivíduos não agirão de modo egoísta para garantir sua máxima satisfação, colocando os outros em uma situação desfavorável. Para Pareto, a gestão de recursos torna-se um fator chave, aqui, para evitar a agitação civil (mas essa é uma discussão totalmente diferente).

Portanto, para todos os conjuntos de possibilidades nos quais $\{a, b$, c) são apresentadas para agentes como escolhas possíveis, a Eficiência de Pareto nos dirá que a escolha razoável (para 1 e 2) é preferir (b), já que escolhas moderadas são mais propícias a levar a resultados eficientes tais como: 


$$
\begin{aligned}
& a-b<b-c \\
& -2 b<-a-c \\
& b<a / 2+c / 2
\end{aligned}
$$

Assim, se aumentarmos o número de situações sociais e escolhas sociais, o quadro aqui tornar-se-á cada vez mais complexo. Essa situação também supõe um cenário de equilíbrio não forçado (ou seja, ambas as partes podem alcançar uma situação social factível). Isso é o que chamamos de cenário max-mini. Uma característica interessante desse cenário é que, em termos de escolha social, ele implica que os agentes podem chegar a melhores resultados (a longo prazo) ao escolher preferências que são menos desejáveis de acordo com seus próprios critérios (ou seja, agir de modo egoísta pode significar irracionalidade econômica).

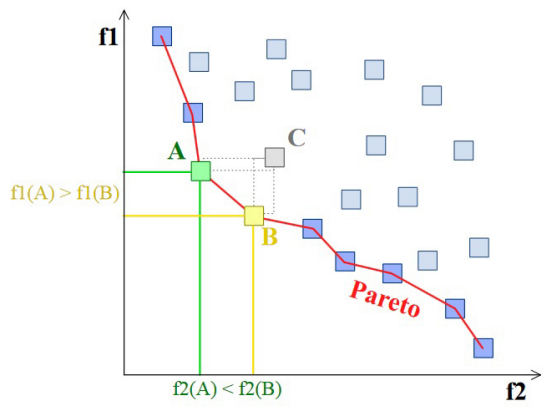

O gráfico acima oferece um exemplo de tal cenário. Considerando os blocos como escolhas possíveis, a maioria dos pontos de equilíbrio entre (f1) e (f2) ocorrerá na parte mais baixa do gráfico. Observe, desse modo, que dois desses estados disponíveis são desejáveis tanto para (f1) quanto para (f2) e são, portanto, "ótimos" em termos max-mini. Outros pontos podem ser um ponto de equilíbrio em termos econômicos (ou seja, há quantidade suficiente desses bens para ambos os agentes), mas a escolha desses bens implicaria que um desses agentes acabe em condições piores do que o outro no final do processo de escolha. Esse é o núcleo do "princípio da diferença" de Rawls. ${ }^{7}$

Pareto também concebe cenários similares nos quais tal distribuição de mercadorias não é possível. Nesse caso, o ponto de eficiência é aquele no qual o conjunto "menos pior" de escolhas favoráveis é oferecido ao 
maior número de agentes na situação ideal de escolha. Isso é chamado, em economia, de ponto de felicidade - também um cenário mini-max.

Finalmente, um último cenário é apresentado na situação ideal, no qual todos os bens disponíveis são ruins ou não estão à disposição (pense na época de pós-guerra na Alemanha, Japão ou Vietnã). Esse seria um cenário mini-mini.

Nesses dois últimos cenários, uma Eficiência de Pareto é impossível. Dada que ela é considerada um princípio da racionalidade econômica na maior parte da literatura do pós-guerra, qualquer cenário, enquanto tal, torna-se um ponto não desejável ou, se você preferir, um sistema irracional de distribuição.

\section{b) Uma teoria econômica da democracia}

Arrow, sob forte influência de Pareto, tentou controlar ainda mais os elementos do critério de Mill para a escolha. Primeiramente, ele defenderá que ter uma preferência significa somente que alguém é capaz de expressar uma hierarquia de valores ou de escolhas de acordo com os dois princípios gerais de conectividade e transitividade. ${ }^{8}$ Ter uma preferência, então, significa que é possível que (A1) possa expressar uma hierarquia e que (A2) mantenha a coerência interna de uma hierarquia de valores. ${ }^{9}$ É muito importante notar que Arrow não se importa com as motivações que estão por trás do processo de escolha de uma preferência. O que importa é que o indivíduo possa e expresse um conjunto consistente de preferências. Isso é verdade em relação ao modo pelo qual escolhemos nossos sabores favoritos de sorvete ou nossos candidatos favoritos em uma eleição. Qualquer agente racional, para Arrow, manter-se-á consistente em suas opiniões, por exemplo, quando diz preferir limão a laranja e laranja a melão, isso significa que ele preferirá limão a melão (de acordo com A2). Isso, certamente, é uma noção muito fraca de racionalidade ${ }^{10}$ na medida em que exige somente que o agente mantenha uma consistência mínima em sua própria expressão de preferências.

Mas como passamos de uma ordenação individual para uma ordenação social de preferências? 
Arrow chamará de "função do bem-estar social"11 o processo através do qual as preferências individuais são representadas em uma eleição. Os eleitores serão capazes de decidir sobre um número de mercadorias (objetos da escolha) que irão constituir um estado social (um conjunto possível de mercadorias) que representa ordenações individuais de preferências. A função do bem-estar social é tal que um conjunto de ordenações $(R)$ de eleitores diferentes será levado em consideração de modo que para quaisquer dois estados sociais $\mathrm{x}$ e y de uma dada ordenação social, R será obtido. ${ }^{12}$

Isso ocorre independentemente da expressão individual em relação a quaisquer tipos de preferências. A regra sobrepõe-se às preferências individuais de acordo com a vontade geral. Assim, percebo os perigos de sugerir que Arrow está seguindo uma concepção clássica de vontade geral, mas, de fato, uma vez que analisamos as condições sob as quais a função de bem-estar social opera, tornar-se-á cada vez mais claro que Arrow está se baseando em uma noção liberal clássica de democracia.

Para Arrow, devemos primeiramente perguntar quais são as condições que satisfazem a forma de um sistema democrático. Se pudermos organizar os critérios segundo os quais pensamos a democracia, qual seria o conjunto geral de regras que precisaríamos seguir para fazer com que uma eleição pudesse ser chamada de democrática ou para o estabelecimento de bem-estar social?

Arrow, em sua tese Social Choice and Individual Values ${ }^{13}$, afirma que uma (e talvez qualquer) definição plausível de democracia é incompleta. Isso significa, em termos primeiramente desenvolvidos por Gödel, que o conjunto de requerimentos estabelecidos de modo a chegar à conclusão de que "p é o caso" acaba levando a que " p é o caso". O ato de votar é importante, aqui, porque é o momento no qual indivíduos escolhem um certo conjunto de preferências sociais que estão representados em um candidato ou em uma proposta política. Se há algo profundamente paradoxal no ato de votar, então a ideia toda de democracia irá ruir, afinal de contas, mesmo formas diretas de representação pressupõem a existência de algum tipo de eleição.

Por um lado, é suficiente, para Arrow, que indivíduos expressem suas preferências individuais de acordo com os critérios de transitividade e conectividade. Por outro lado, ele insiste em um número de condições 
de razoabilidade para se obter uma constituição aceitável (nesse caso, uma eleição aceitável). Até então, sabemos que a função de bem-estar social será tão complexa quanto o número de estados sociais disponíveis, a multiplicidade de estados sociais escolhidos e o número de indivíduos.

Além disso, as condições nas quais os indivíduos votam precisam ser tais que um conjunto de "critérios de controle" seja estabelecido. Tais condições são:

(C1) Não-ditadura (ND): a função de bem-estar social deve levar em conta os desejos de vários indivíduos. Ela não pode simplesmente expressar as preferências de um único indivíduo.

(C2) Universalidade (U): para qualquer conjunto de preferências de voto individual, a função de bem-estar social deve abranger uma ordenação única e completa de escolhas sociais. Isso deve ocorrer de modo que resulte em uma ordenação completa de preferências para a sociedade (de acordo com A1) e, necessariamente, forneça a mesma ordenação toda vez que as preferências dos eleitores forem apresentadas do mesmo modo (de acordo com A2).

(C3) Independência de alternativas irrelevantes (IAI): alternativas irrelevantes não podem causar impacto em alternativas relevantes. Ou seja, uma mudança na expressão de um subconjunto irrelevante não pode influenciar a ordenação do subconjunto relevante - o movimento estratégico de valores irrelevantes buscando afetar os valores relevantes é, assim, evitado, assim como a incompletude do subconjunto relevante.

(C4) Monotonicidade (Mono): para todo conjunto individual de escolhas 'r' corresponderá uma ordem social 'R'. Qualquer melhoria em 'r' implica uma melhoria em ' $\mathrm{R}$ ' ou, na pior das hipóteses, a repetição do status quo ante. A uma melhoria em ' $r$ ' nunca poderá corresponder um declínio da ordenação social em ' $\mathrm{R}$ '. Um indivíduo não deverá votar contra uma proposta que ele deseja que seja aprovada de modo a promovê-la (de acordo com C2 e A2). Em outras palavras, os valores presentes em r serão mantidos em $\mathrm{R}$.

(C5) Não-imposição (NI): os indivíduos são livres para decidir sua ordem de preferência sem coação externa. Qualquer resultado é possível dentro de um dado conjunto no início de uma eleição, e qualquer ordenação é possível dentro desse conjunto. A função de bem-estar social tem um espaço irrestrito dentro de um conjunto possível de alternativas. 
Em teoria, Pareto indicou que qualquer distribuição de bens, em uma situação ideal, sempre significará que o ganho de um indivíduo (ou grupo social) causará uma perda para outro indivíduo (ou grupo social). Nesse sentido, processos de troca jamais serão uma situação da qual as partes se beneficiarão igualmente. Uma exceção ocorre quando as condições para um processo livre e informado de troca, no qual as partes podem expressar e negociar suas preferências com um mínimo de interferência, levam a um estágio no qual o ganho de um indivíduo não provocará perda para um outro. Pareto expressou a plausibilidade da noção de "mão invisível" do mercado que poderia ser capaz de mitigar o processo de perda e ganho sociais em um equilíbrio hipotético.

Arrow foi capaz de demonstrar que tal posição ideal, chamada de "primeiro princípio da economia de bem-estar", seria matematicamente possível em uma situação idealizada, dado que os indivíduos estariam em uma situação de "perfeita informação"14 e que certas condições para a ordenação de preferências estariam presentes. Tais critérios de escolha são semelhantes àqueles que analisei acima e também levam, mesmo que haja critérios bastante estreitos para a razão e a racionalidade na escolha, a cenários paradoxais em relação à função de bem-estar social. ${ }^{15}$ Observe-se que as condições de Arrow para a escolha são as mesmas condições que Pareto desenvolveu para sua ideia de eficiência e são, para Arrow, equivalentes a um critério de razoabilidade. ${ }^{16}$

Nesse sentido, o bem-estar social reproduz preferências individuais indiretamente mesmo que elas sejam expressas diretamente e também evita que questões irrelevantes tornem-se decisivas na definição da função de bem-estar social. Arrow não justificará seus princípios de ordem democrática mais detidamente. Seu argumento principal é que eles "pareçam sólidos" e estejam de acordo com a interpretação moderna sobre aquilo que é exigido para que uma democracia seja considerada como tal. Note que nenhuma dessas condições é suficiente sozinha para garantir a existência de um sistema democrático. Elas são necessárias conjuntamente para uma concepção suficiente de democracia - e observe que essa concepção suficiente se assemelha bastante à democracia constitucional que encontraremos na estrutura básica para a equidade institucional, depois, em Rawls.

Isso ocorre porque os indivíduos não agirão sem buscar um benefício individual, mesmo às custas dos outros, sem alguma espécie de marco 
regulatório ou rede de segurança. Em um sistema de oportunidades e preferências desiguais, os indivíduos não farão escolhas bem-ordenadas e previamente esperadas apenas para se submeter à elegância dos apontamentos matemáticos de Arrow. ${ }^{17}$ Talvez seja por esse motivo que o próprio Arrow concentrou-se em elementos relativos a valores no final de sua tese, observando que algum tipo de "diretriz" ética é necessária para a "solidez" da proposta democrática. ${ }^{18}$

\section{c) Cálculo de utilidade e justiça como equidade}

Nesse ponto, parece-me, Rawls vê os limites da teoria utilitarista ${ }^{19}$ e decide concentrar-se em uma abordagem kantiana da teoria política. Considerando apenas os elementos do cálculo de utilidade, não chegaremos, em Rawls, a um cenário no qual pudéssemos construir uma função de bem-estar social. Mas está claro que, sem Arrow, Rawls não poderia ter desenvolvido sua ideia de posição original nem poderia ter construído as condições para os princípios de justiça. ${ }^{20}$

Considero importante enfatizar, entretanto, que a doutrina do liberalismo é primeiramente entendida por Rawls, pelo menos em $A$ Theory of Justice, como um método. Isso significa que ideais como os de posição original, equilíbrio reflexivo e juízos morais bem ponderados não são, primeiramente, entendidos como questões fáticas, mas, ao contrário, como condições nominais para que uma doutrina particular de liberalismo que Rawls deseja se desenvolva.

A ideia de posição original inicia com uma suspeita compartilhada entre filósofos modernos contra a experiência pessoal enquanto justificativa da expressão de prioridades políticas. Parece que Rawls quer levar ainda mais longe o processo de despersonalização, criado por Kant no desenvolvimento do imperativo categórico como procedimento para validar a conduta. Afinal de contas, a posição original requer não apenas que as partes vão além daquilo que suas motivações sensíveis de conduta exigiriam: ela, na verdade, requer que as partes ajam como se não existissem motivações sensíveis para a conduta, história pessoal e assim por diante.

Esse exercício hipotético, então, colocaria os indivíduos em uma situação na qual, primeiramente, "preconceitos" ou "julgamentos" prévios a 


\section{4}

respeito da conduta e experiências prévias seriam abandonados quando os indivíduos entrassem no procedimento de escolha racional de valores para uma função de bem-estar social. Por que isso ocorre? Há duas razões principais: por um lado, temos a confiança de Rawls na condição kantiana de que a razão isoladamente, ou seja, o uso especulativo da razão, pode fornecer um quadro dentro do qual os valores são importantes; por outro lado, Rawls está se baseando profundamente em insights da teoria econômica.

A noção de uma posição original é, então, um requisito para a solidez do equilíbrio reflexivo em uma função de bem-estar social e esse equilíbrio reflexivo é uma imagem espelhada do já mencionado equilíbrio de Pareto, ou seja, o ponto no qual uma mudança não necessariamente implicaria uma situação em que o beneficio de um indivíduo (ou grupo) em uma função de bem-estar social não tornaria pior a situação de outro indivíduo (ou grupo). ${ }^{21}$

Gostaria, agora, de interrogar como se parecem os indivíduos na posição original. Considerando que Rawls estabelece o caráter hipotético de tal posição e que ela pertence ao âmbito da teoria ideal, acredito que a questão permanece válida: como se parecem os indivíduos na posição original hipotética?

Estariam esses indivíduos na posição original conscientes das potenciais consequências de suas escolhas de valores e teriam eles conhecimento sobre as condições futuras, por exemplo, de modo que não passar fome fosse preferível a passar e, portanto, políticas e princípios que evitassem a fome seriam preferíveis a políticas e princípios que fariam algumas pessoas passar fome, mas que poderiam fazer com que pessoas ricas realizassem seus sonhos mais extravagantes?

Nesse caso, faz sentido dizer que os indivíduos na posição original estão abandonando suas opiniões sobre a realidade social corrente quando alcançam a situação na qual estão fazendo escolhas sociais? Penso que isso é completamente contra-intuitivo, se seguirmos uma interpretação canônica do que o Rawls está propondo. Em uma interpretação puramente indulgente, bastaria conceber uma posição possível na qual os indivíduos, de alguma forma intuitiva, saberiam que condições mínimas de justiça social são preferíveis a condições de injustiça social.

Nesse sentido, insisto que, em seu núcleo, $A$ Theory of Justice está lidando com um método para a teoria política, na primeira parte, e esse 
método diz respeito às condições nas quais uma função de bem-estar social ideal em uma sociedade liberal é possível. Parte desse núcleo supõe que os indivíduos preferirão, intuitivamente, não sentir dor ao invés de sentir; que preferirão valores que potencialmente garantirão mais liberdade, e não menos. A outra parte do método, talvez menos persuasiva, lida com um tipo de afastamento da realidade social corrente quando se está concebendo essas preferências. Para Rawls, esse é um aspecto fundamental para eliminar prejuízos e vantagens potenciais com os quais os indivíduos possam estar "infectados" quando desenvolvem seus julgamentos de valor. Julgamentos de valor bem ponderados serão justificados, então, quando forem válidos dentro do escopo da posição original e potencialmente conduzirem a sociedade a uma posição de equilíbrio reflexivo, ou seja, uma posição na qual a expressão de preferências individuais por um política ou plano de vida não for potencialmente danosa para a possível expressão de outras preferências individuais.

"Razoável", então, rapidamente torna-se o adjetivo chave para Rawls, já que significa as considerações intuitivas que indivíduos hipotéticos são capazes de justificar do ponto de vista de uma posição original hipotética. Claramente, Rawls ainda acredita nos poderes da razão especulativa e na possibilidade de separar considerações de valor das contingências sociais. Do ponto de vista de uma teoria ideal, isso vai muito além do que imaginou Kant - mas Rawls acredita que a validade da tese kantiana tem apoio naquilo que a economia política nos diz sobre a competição e colaboração potenciais entre indivíduos em um modelo de trocas.

Entretanto, o modelo proposto por Pareto e adotado por Rawls pressupõe condições para esse processo de escolha: ele pressupõe um número de situações ideais e indivíduos ideais necessários para estabelecer uma certa posição de troca de valores ideais. Ele também pressupõe que os indivíduos não estão sob estresse de experiências prévias quando fazem escolhas "razoáveis" sobre suas preferências.

Essas são, certamente, pressuposições incrivelmente pesadas. Rawls sabe disso e não é uma coincidência que a segunda parte de $A$ Theory of Justice seja um denso tratado a respeito da importância de um quadro institucional que dará apoio aos indivíduos que serão capazes de escolher de tal forma. $\mathrm{Na}$ verdade, acredito que a segunda parte do livro nos fornece uma abordagem histórica de como uma função de bem-estar social 
ideal, do ponto de vista do liberalismo político, é possível. Se olharmos para o núcleo representado pela igual liberdade, pela justiça distributiva e pelos deveres e obrigações, estamos olhando para a história da formação do Estado moderno - que claramente toma forma a partir das revoluções constitucionais da Inglaterra, Estados Unidos e França -, e é dentro dele que Rawls vê o potencial para uma realização desse projeto.

Isso responderia à questão de "quem seriam os indivíduos na hipotética posição original": os indivíduos que estão no término do processo de secularização e emancipação representado pelo surgimento do Estado moderno.

Isso significa duas coisas: primeiro, que um Estado moderno e liberal é intuitivamente preferível a um Estado não moderno, não secular. Isso se dá principalmente porque as condições nas quais uma função de bem-estar social razoável é possível estão presentes apenas nos atuais e existentes Estados modernos. A segunda é que esse movimento, por causa de sua necessidade intuitiva, é defensável para Estados que ainda não são modernos, e que indivíduos nesses Estados se moverão em direção a posições mais liberais e seculares em relação a direitos - dadas as oportunidades para tal.

A segunda parte do argumento encontra-se nas afirmações universais sobre a personalidade moral, ou personalidade moral potencial, na terceira parte do tratado de Rawls: quando lidamos com a importância do bem, o senso de justiça e o papel da justiça, estamos lidando, pelo menos de acordo com Rawls, com características que são compartilhadas universalmente pelos seres humanos. É difícil argumentar contra a principal tese de Rawls: os ideais de liberdade de expressão e igual oportunidade podem muito bem ser contingências históricas peculiares a culturas ocidentais, com uma história sombria e complexa. Ainda assim, nossas razões para implementar esses direitos são sólidas e não temos razão para acreditar que outros não irão querer esses mesmos direitos, que eles não compartilham nossos sentimentos morais na medida em que eles estão ligados a princípios de justiça fundamentais (estar livre de escravidão, igual oportunidade entre indivíduos, possibilidades abertas para escolhas de vida etc.). A questão, então, é aumentar o alcance de tais direitos: se a doutrina da filosofia moderna criou um aumento sem precedentes na qualidade de vida em circunstâncias nas quais esses princípios foram efetivamente implementados, então por que não deveríamos tentar implementá-los em larga escala? Nesse sentido, a tese liberal torna-se irresistível em Rawls. 


\section{d) Em direção a uma crítica histórico-fenomenológica da escolha}

É interessante notar que a abordagem sugerida tanto por Arrow quanto por Rawls não faz economia no uso de "tipos ideais". Não considero que o uso de uma estrutura "ideal" para eleições, para processos de voto e para as condições para a democracia seja inteiramente uma coincidência. $\mathrm{Na}$ verdade, Arrow e Rawls são profundamente weberianos quando tentam estabelecer um modo através do qual uma estrutura ideal é realizável. Observe que Arrow dirá que as preferências individuais estão, de alguma forma, presentes nas escolhas sociais, e Rawls nos lembra bastante Weber quando escreve que valores e ideais são razoáveis na medida em que podem ser justificados pelos membros de uma sociedade, ao mesmo tempo em que não são realmente empíricos.

Entretanto, até onde sei, Rawls menciona Weber apenas uma vez em $A$ Theory of Justice. A menção está escondida no final do livro, ${ }^{22}$ em uma nota de rodapé, na qual Rawls acusa tanto Weber quanto Max Scheler (tanto quanto sei, essa é a única vez que Scheler é mencionado por Rawls) de fornecerem uma noção estratificante e rígida de vocação que não permite mudança ou mobilidade social e que não explica mudanças nas preferências e motivação sociais.

Ainda assim, sem uma concepção não estática de tempo dificilmente há qualquer chance de fazermos as preferências terem algum sentido. Há todo um conjunto de expectativas e representações que são pressupostas no momento da decisão. Constituímos valores em relação a nosso passado, nossa sociedade e nossa herança. Isso significa que alguém criado em um contexto racista sempre será racista? De forma alguma. Mas esse contexto terá grande influência na maneira pela qual esse indivíduo, por exemplo, resistirá ao racismo e constituirá sua própria perspectiva a respeito de como e porque o racismo é errado. Nesse sentido, a realidade dos valores para indivíduos ou grupos é construída socialmente, e não a partir de um rascunho, de acordo com o desejo do filósofo.

Nesse sentido, até mesmo motivações estratégicas precisam ser postas em contexto, assim como a interação que define tal estratégia. Por que minha atitude em relação aos outros me leva a não ter confiança em sua habilidade de colaborar ou compartilhar um determinado conjunto de valores comigo? 
Ao nos concentramos na determinação institucional dos tipos ideais, podemos tomar como garantida a interação social e ignorar um importante aspecto da "equação", ou seja: a constituição de tipos ideais está necessariamente conectada à construção histórica desses tipos ideias. Os processos de significação da estrutura de uma fenômeno cultural ou de uma concepção ideal é o resultado de uma disputa histórica que está ligada a um número de interpretações do fenômeno e do ideal, o que significa que não há tipo ideal institucional que não seja uma interação com sujeitos, e que não há sujeitos que estão fora da interação enquanto concebem um tipo ideal. Certamente, fazendo isso, estamos nos afastando do terreno de um historicismo weberiano e indo em direção a um estruturalismo fenomenológico.

Se somos capazes de reconhecer a importância de um equilíbrio reflexivo entre princípios de justiça ideais que são decididos de forma representativa, e uma pedagogia moral que informa a respeito das decisões sobre concepções de bem, precisamos também entender que esses processos não são estáticos nem ocorrem da mesma forma ou no mesmo ambiente. Refletir essa multiplicidade de concepções e o conflito entre elas é precisamente o que está em jogo para uma legislação escrita que busca reforçar a sociabilidade entre diferentes indivíduos - e entre diferentes socializações que vêm encarnadas neles.

1 "Running against the boundaries of our cage". WITTGENSTEIN. Lecture on Ethics. Disponível em http://sackett.net/WittgensteinEthics.pdf (último acesso: 28/08/2012).

${ }^{2}$ RAWLS, John. A Theory of Justice. (1974, repr. Cambridge: Harvard University Press, 1999).

3 “"J] ustice as fairness holds that, with regard to the constitutional essentials and questions of basic justice, and given the existence of a reasonably well ordered constitutional regime, the family of basic political values expressed by its principles and ideas have sufficient weight to override all other values that may normally come into conflict with them". RAWLS, Justice as Fairness: a restatement, p. 183. Também: "from the standpoint of moral theory, the best account of a person's sense of justice is not the one which fits his judgments prior to his examining any conception of justice, but rather the one which matches his judgments in reflective equilibrium". RAWLS, A Theory of Justice, p. 43.

${ }^{4}$ Ibid, p. 185

${ }^{5}$ Note-se que o desenvolvimento dos termos dos dois princípios de Justiça em $A$ Theory of Justice (p. 52-86) é baseado nos debates sobre a posição de equilíbrio de distribuição de bens 
na economia política. Tal debate é apenas possível a partir das reflexões de Pareto ( $A$ Theory of Justice, p. 58n) sobre equidade na distribuição de bens.

${ }^{6}$ RAWLS, John. Lectures on the History of Political Philosophy, p. 260.

${ }^{7}$ RAWLS, John. A Theory of Justice, p. 152.

${ }^{8}$ ( $\mathrm{x}, \mathrm{z}$ ) são candidatos, $\mathrm{P}=$ preferência, $\mathrm{I}=$ indiferença, $\mathrm{R}=$ preferência ou indiferença no contexto. Conectividade: para todos (os objetos de escolha no conjunto) $\mathrm{x}$ e y, tanto $\mathrm{x} R \mathrm{y}$ ou y R x. (A1); Transitividade: para todo x, y e z, xRy e yRz implicam xRz (A2). Assim, alternância ('ou') e conjunção ('e') de relações R representam ambas as propriedades de uma ordenação para todos os objetos de escolha. Nesse sentido, as possibilidades de ordenar preferências serão assim definidas: D1: xPy <-> $\sim$ (yRx) (de acordo com A1); D2: xIy <-> \{xRy e yRx) (de acordo com A2); D3: $x \mathrm{Ry}<->\sim \mathrm{yPx}$.

${ }^{9}$ ARROW. A difficulty in Social Welfare. In: ARROW. Collected Papers of Kenneth J. Arrow, Vol. I: Social Choice and Justice, pp. 26-7.

${ }^{10}$ Ver ARROW. Current Developments in the Theory of Social Choice. In:ARROW. Collected Papers of Kenneth J. Arrow, Vol. I: Social Choice and Justice, p. 163.

${ }^{11}$ ARROW. Social Choice and Individual Values, pp. 22-33.

12 Para Arrow: xPy indica "preferência social" por x em detrimento de y (x é selecionado ao invés de y, pela regra); xly é indica "indiferença social" entre x e y (ambos são ordenados igualmente de acordo com a regra) e xRy indica tanto "preferência social" de x em relação a y quanto "indiferença social" entre x e y (x é ordenado da mesma forma que y de acordo com a regra).

${ }^{13}$ ARROW, Kenneth J. Social Choice and Individual Values. New Haven:Yale University Press, 1963.

${ }^{14}$ Uma situação de perfeita informação é aquela na qual os indivíduos conhecem o conjunto possível de preferências disponível para todos os outros indivíduos em uma situação ideal. Em teoria dos jogos, isso significa que todos os possíveis movimentos de todos os jogadores em uma partida são visíveis para todos os outros jogadores (e que eles têm um entendimento similar a respeito do conjunto de regras do jogo). Em teoria econômica, isso significa que as partes conhecem os riscos e implicações de seus movimentos e são capazes de se mover livremente em direção a estados ou bens de sua preferência. Arrow está consciente da artificialidade dessa situação, mas é matematicamente possível conceber tal estado, e isso é suficiente para tornar viável o equilíbrio de Pareto - pelo menos de um ponto de vista econômico.

${ }^{15}$ As peculiaridades do assim chamado "paradoxo do voto" podem ser encontradas na tese de Arrow, Social Choice and Individual Values.

${ }^{16} \mathrm{Na}$ verdade, Arrow fazia parte do grupo de economistas que demonstraram a possibilidade do equilíbrio de Pareto.

${ }^{17}$ Daí, por exemplo, a necessidade do princípio da diferença em Rawls (ver Rawls. Justice as Fairness: A Restatement, pp. 158-9).

${ }^{18}$ A importância da ordenação social de preferências mínimas, ou consenso social, encontra-se em Arrow. Social Choice and Individual Values, pp. 81-6. Isso está ligado à importância de uma 
racionalidade coletiva que servirá como "controle" para o auto-interesse e a manipulação no processo democrático. Arrow claramente fica desconfortável quando lida com essas questões e a maior parte de seus insights sobre o tema são vagos e serão explorados de modo mais completo somente na apropriação que Rawls faz do equilíbrio de Pareto como equilíbrio reflexivo.

${ }^{19}$ Arrow prefere chamar sua teoria de ordenadora, ao invés de utilitarista. Esse é o resultado do que ele considera uma reapropriação maior da noção de utilidade e escolha de Mill. Para Arrow, seu critério de preferência é uma elaboração mais fraca e mais modesta do critério de decisão de Mill, e está baseado em um requisito mínimo para a eficiência da decisão: transitividade e conectividade. Na visão de Arrow, isso não é mais utilitarista no sentido proposto por Mill, mas ordenador, no sentido de que iguala razão e eficiência de escolha. Se uma escolha é eficiente (transitiva e conectada), então é uma escolha racional (ARROW. Some OrdinalistUtilitarian notes on Rawls' Theory of Justice. In: ARROW. Collected Papers of Kenneth J. Arrow, Vol. I: Social Choice and Justice, p. 98). Interessantemente, Arrow considera que essa noção de ordenação é totalmente compatível com a posição de Rawls. Isso não é surpreendente dado que Rawls também adota o modelo do equilíbrio de Pareto para seu equilíbrio reflexivo, e que ambos baseiam-se fortemente na noção de perfeita informação (embora de modos diferentes, como veremos adiante).

${ }^{20}$ Compare-se, por exemplo, a descrição do princípio de diferença em A Theory of Justice (pp. 61-3) e sua importância para um "sistema de cooperação" com o que acabei de analisar em Arrow e Pareto. Observe-se também que toda essa discussão ocorre nos mesmos moldes daquela feita por Mill em Political Economy e em Utilitarianism.

${ }^{21}$ Ver o parágrafo 16 de A Theory of Justice, e p. 65 de Justice as Fairness.

${ }^{22}$ Rawls, John. A Theory of Justice, p. 479, nota. Weber retorna, entretanto, em Justice as Fairness (p. 154, nota 29) em uma importante nota de rodapé que trata da inevitabilidade da "perda" e da tragédia humana com o surgimento de novas organizações econômicas.

\section{Referências bibliográficas}

1999. A Theory of Justice. Cambridge: Harvard University Press. .1983. Collected Papers of Kenneth J. Arrow, Volume I: Social Choice and Justice. Cambridge: Harvard University Press.

.1984. Collected Papers of Kenneth J. Arrow, Volume IV:The Economics of Information. Cambridge: Harvard University Press.

.2003. Justice as Fairness: A Restatement. Cambridge: Harvard University Press.

.1996. Political Liberalism. New York: Columbia University Press. 
.2008. Principles of Political Economy. New York: Oxford University Press (USA).

ARROW, Kenneth J. 1963. Social Choice and Individual Values. New Haven:Yale University Press.

BER GER, Peter; LUCKMANN, Thomas. 1967. The Social Construction of Reality. New York: Doubleday \& Company.

MILL, John Stuart. Utilitarianism. 2002. Indianapolis: Hackett Publishing Company.

PARETO,Vilfredo. 2007. Considerations on the Fundamental Principles of Pure Political Economy (Routledge Studies in the History of Economics). Routledge: London.

RAWLS, John. 2007. Lectures on the History of Political Philosophy. Cambridge: Harvard University Press.

RAWLS, John; FREEMAN, Samuel (ed.). 1999. Collected Papers. Cambridge: Harvard University Press.

WEBER, Max; HEYDEBRAND, Wolf (ed.). 1994. Sociological Writings. New York: Continuum.

WITTGENSTEIN, Ludwig. Lecture on Ethics. Disponível em http:// sackett.net/WittgensteinEthics.pdf (último acesso: 28/08/2012). 